\title{
Research on the Development Pattern of Sports Tourism in 18-hole Village under the Accurate Poverty Alleviation
}

\author{
Lizhong Wen \\ College of Sports and Science, Jishou University, Jishou, Hunan 416000 \\ wenlizhong1107@163.com
}

\section{Keywords: Precise Poverty Alleviation 18-hole Village Sports Tourism Development Mode}

\begin{abstract}
In the new situation, precision poverty alleviation has become the core project of national poverty alleviation strategy and an effective way to promote the all-round and coordinated development of rural economy. The poverty alleviation of rural tourism is the most important part of the poverty alleviation. With the guidance of the concept of precise poverty alleviation, the 18-hole Village in Huayuan County of Hunan Province has scientifically developed sports tourism resources from multiple perspectives, giving full play to the advantages of the existing regional sports culture and natural tourism resources, vigorously developing the sports tourism industry, and comprehensively promoting the new rural construction process.
\end{abstract}

\section{Introduction}

With the continuous development of tourism, the development of sports tourism industry has become the focus of the party and state. In the context of precision poverty alleviation, the importance of regional sports tourism development further appears. Based on the concept of precise poverty alleviation and in light of its own different aspects, the 18-hole Village started to develop the sports tourism resources efficiently. On the basis of displaying the regional characteristics, it promoted the steady development of the regional economy, realized the goal of getting rid of poverty and eventually moving towards a well-off society. Therefore, in the development of the sports tourism industry, The 18-hole Village of Huayuan County in Hunan Province has stepped into the tourism development poverty alleviation ranks.

\section{Accurate Poverty Alleviation and Patterns}

Accurate Poverty Alleviation. "True Poverty Alleviation" and "Alleviating Poverty Alleviately" are the core of "precise poverty alleviation", while the poor and the poor resources are two important elements that can not be ignored.In the tide of building a well-off society in an all-round way,poverty alleviation has become one of the important ways in which the poverty alleviation strategy can be implemented.The multi-faceted scientific integration of the existing resources of the poor and the localities can create a new economic growth point for the poor areas so that those who are truly poor in the region will embark on the path of getting rid of poverty and becoming prosperous, and their quality of life will be upgraded.

Precise Poverty Alleviation Mode. In terms of time, the reduction in the population of the regional poverty is mostly after the reform and opening.In other words, the poverty reduction effect of the closed-door rehabilitation system is not very effective and requires an open-minded attitude. The reduction of the poor population is affected by internal and external factors, and the factors that cause poverty are also reflected in many aspects, for example: the lack of advanced concepts, poor traffic conditions, poor natural environment,etc..Compared with internal factors, the external causes are more obvious and external support plays an important role in raising poverty alleviation benefits. 


\section{The Development Mode of Sports Tourism in the 18-hole Village in the Context of Targeted Poverty Alleviation}

The Precise Poverty Alleviation Model of the 18 - hole Village. The 18-hole Village is located in the southwestern part of Paibi township, Huayuan County, Hunan Province, It is a poverty-stricken area, and the difficulty of poverty alleviation is quite large. In 2013, general secretary Xi Jinping visited Xiangxi Tujia and Miao Autonomous Prefecture in Hunan Province, and put forward the concept of "precision poverty alleviation" for the first time in the 18-hole Village of Huayuan county. In this context, the 18-hole Village embarked on a path of precision-oriented poverty alleviation. The model of precise poverty alleviation was based on the files and cards havebeen established and fixed-point comparisons. It was led by government departments and implemented diversified investment and institutionalized accountability. Subsequently, this model of precise poverty alleviation has been continuously adopted in other regions of our country, and the effect of it has been remarkably improved.

However, from the past experiences and lessons, this model of precise poverty alleviation has some shortcomings. Once the long-term mechanism is constructed, loopholes are easily encountered Return to poverty. In 2017, prior to the convening of the NPC and CPPCC sessions, Hunan Province announced that under the layers of evaluation and assessment, the 18-hole Village has already met the requirement of getting out of poverty. Compared with 2013, the per capita net income has increased substantially, and has reached 8313 yuan. The impoverished households in the 18-hole Village were lifted out of poverty, and the "poverty" hat was actually removed from the village. Up to about three years of hard work, the 18-hole Village displayed its brand-new appearance in front of the world with obvious changes in living environment and ideas of rural residents. On the road to precision poverty alleviation, the 18-hole Village party branch has played a key role, they have been improved transport and other infrastructure, implemented the power, water and access roads successfully and constructed special tourist trails. On this basis, the 18-hole Village, with its own advantages in all aspects, energetically developed specialty farming industries such as bee-keeping, kiwi fruit, natural vegetables and country-specific tourism, opened up a completely new situation. Visitors to the tourist Significantly increased, with Miao characteristics as the base for leisure tourism in 2016 attracted more than two hundred thousand tourists.

Feasibility of Exploiting Sports Tourism in 18-hole Village with Accurate Poverty Alleviation. From an objective point of view, there are many places where the targeted poverty alleviation can be duplicated, but there are also shortcomings. The 18-hole Village belongs to a contiguous and impoverished area, most of the infrastructure facilities are so weak that need a number of money to be substantially improved., the loan is one of the ways to get money, but it needs to have a certain ability to repay. At the same time, special breeding industry is poverly good, but in the process of precise poverty, poor households have a strong dependence on the support, the government propaganda and marketing guidance are the corresponding ways of poverty alleviation, but poverty alleviation in the agricultural industry, due to the related factors, the interests of enterprises and farmers are prone to bias. On the precise path for poverty alleviation, 18-hole Village has become a representative village, the entire villiage, to increase the visitors, but from a long-term point of view, as time goes on. However, in the long run, whether the benefits of tourism in the 18-hole Village will change as time goes by Continuous improvement will be a question worth pondering. If you want to stop returning to poverty and go smoothly to a well-off road, there is still a long way to go for the 18-Hole Village. We should pay attention to the diversification of the precise poverty alleviation model.

In the case of 18-hole Village, there are a large number of karst caves, and some of them have very high value in tourism development and utilization. They have good natural environment advantages. In the case of 18-hole Village, there are a large number of karst caves, and some of them have very high value in tourism development and utilization. They have good natural environment advantages. Under the role of propaganda and the like, outdoor sports enthusiasts have obviously increased. For outdoor activities, different types of social groups also come here for leisure travel. In view of this situation, the 18-hole village is particularly important in the 
development of sports tourism in the context of precision poverty alleviation. Building a rationalized sports tourism base is a good mode of long-term poverty alleviation, in line with the objective requirements of the development of the times. The development of sports tourism is conducive to making full use of the existing resource advantages of 18-hole Village, highlighting the features of tourism in the region, attracting more tourists, optimizing the mode of innovation and economic development to a certain extent, presenting a new economic growth point. The industry has become a pillar industry in the region and continues to promote regional economic development in an all-round way. The development of sports tourism can speed up the perfection of infrastructure in the region. According to the sports tourism attractions, the peasants in the region can adopt the special forms of economic development such as "small supermarkets" and "agritainment" to increase the tourists' Increase and improve their living standard smoothly, and smoothly embark on the road to getting rich fortune. This will enrich the daily life of peasants in the region and enhance the cultural level and overall quality in saving, protecting, passing on and developing sports culture.

Precise Poverty Alleviation in 18-hole Village Development of Sports Tourism. Due to its particularity in the contiguous destitute areas, the 18-hole Village must analyze the current mode of using the precise poverty alleviation mode effectively and in a long-term, the latter is the key to avoid the emergence of the phenomenon of poverty. In the process of precise poverty alleviation, Hunan Province objectively evaluated and affirmed the effectiveness of the 18-hole Village. At the same time, according to the spirit of the document "Precise Poverty Alleviation" by the Central Government and the Provincial Party Committee, Hunan province comprehensively and objectively analyzed the development of the tourism and leisure agriculture in the 18-hole Village, and formulated relevant regulations, which showed the importance of the tourism poverty alleviation in the 18-hole Village. Starting with regional farmers, Hunan Province has comprehensively and objectively analyzed the development of tourism in 18-hole Village and all aspects of leisure agriculture and formulated the relevant regulations that show the importance of poverty alleviation in 18-hole Village. Taking the peasants in the region as the starting point, the project of building a tourism-rich people for poverty alleviation project. Under the influence of many factors, the 18-hole Village concentrated in connecting poor poverty-stricken areas such as Luo Xiaoshan Area and Wuling Mountain Area to build tourist quality routes and supported more than 300 villages. In other words, on the path of future development, the beautiful village tour will be one of the effective measures for the 18-hole Village to deepen the model of using precise poverty alleviation and implementing the long-term and accurate poverty alleviation mode.

In the tide of sustained social and economic development, the development of sports industry in all regions in China accelerated, especially in fitness and leisure industry, effectively satisfying the diversified demands for sports consumption of residents in the new era. In the context of precision poverty alleviation, the 18-hole Village should also proceed from all aspects of its own actual situation and, with targeted mode, vigorously develop sports tourism. In accordance with the specific requirements in aspects of fitness and leisure industry, the 18-hole Village should deepen the traditional tourism industry in the region, change the traditional local tourist attractions mode, adopt the global tourism mode, and promote the attractions in a unified network structure system with distinctive integration features.

The 18-hole Village should conduct in-depth analysis of its own advantages and disadvantages at multiple levels. Based on the global tourism mode, it should tap and scientifically integrate various existing sports tourism resources scientifically from multiple perspectives, rationally develop government departments and tourists' objective needs And vigorously develop the sports tourism industry, the fitness and leisure industry should be placed at the core position to create a "green" and "healthy" fitness and leisure tourism industry as an important mode for the development of sports tourism and an important development mode embarked on a well-off way.

In this process, the 18-hole village should skillfully use the sports tourism development model to improve the level of accurate poverty alleviation and increase the strength of poverty alleviation in sports tourism and organic coupling sport and tourism, with the advantage of sports tourism 
resources, derivative characteristic sports tourism products which satisfied by the characteristics of the objective demand of diversified tourists at various levels in the new period.According to the specific construction of the local tourist attractions, the 18-hole Village has cleverly integrated the sports industry, such as fitness and leisure, into the construction, cooperate with well-known enterprises and companies, learn to use modern information technology to promote regional characteristics of sports tourism and marketing various sports tourism products, build brand effect to attract more tourists to visit and sports culture consumption and Comprehensively improve the overall benefit of the accurate model for poverty alleviation in sports tourism.

\section{Conclusion}

In a word, in the context of precision poverty alleviation, the 18-hole Village of Huayuan County, Hunan Province, should apply the development vision and have the overall situation, and analyze the achievements from different angles, in particular, the benefits obtained by the precision poverty alleviation model. The 18-hole Village should build a long - effect model of poverty alleviation with the help of its own existing resource advantages. The 18-hole Village should revolve around the idea of precision poverty alleviation, unit with the existing sports tourism resources, adopt the suitable sports tourism development model. On the basis of scientific development, 18-hole Village should develop the sports tourism industry efficiently, integrate new elements into the development of regional tourism, and achieve effective "precise poverty alleviation" in the process of continuously promoting regional economic development, so as to truly implement the concept of "precise poverty alleviation". It can also inherit and develop the existing traditional sports culture in the area, highlight regional characteristics, Speed up the pace of construction of beautiful countryside, Promote the process of building a well-off society in an all-round way in the new period.

\section{Acknowledgements}

Social Science Research Project of Hunan Provincial Sports Bureau in 2017 (2017XH080); 2017 National Social Science Fund Project of Jishou University (17SKA02)

\section{References}

[1] Bao Mingxiao. Implementing the State Council's Opinion on Accelerating the Development of Sports Industry and Accelerating the Development of Sports Tourism in China [J]. Sports Culture Guide, 2015, (3): 109-111,126

[2] Fan Dongjun. Analysis of Current Situation, Patterns and Countermeasures of Industrial Poverty Alleviation in China from the Perspective of Precise Poverty Alleviation - Based on the Analysis of Xiangxi Prefecture in Hunan Province [J]. Journal of Sichuan Provincial Party Committee, 2016,04: 74-78

[3] Gao Feng. The Road to Ecotourism for Rural Sports Tourism -- and an Overview of Sports Tourism[J]. University Education Science, 2017(1): 10-10

[4] Gong Liuji.Research on the Construction and Innovation Mode of Market-oriented Poverty Alleviation Mechanism under the Governmental Domination - From the Perspective of Precision Poverty Alleviation [J]. Soft Science in China, 2016, (5): 154-162

[5] Lin Yigang, Yang Wenhua. Research on the Precise Poverty Alleviation Dilemma of Rural Tourism in China: Based on the Perspective of Production Factors[J]. Journal of Yunnan National University(philosophical social science), 2017, 34(2): 121-127

[6] Zou Hong, Xie Zhongping.Development of Sports Tourism Culture Resources in China under Healthy China [J]. Contemporary Sport Science and Technology, 2017,7 (30): 158-159

[7] Zheng Liuyun, She Lu. An Analysis of the Problems and Countermeasures of Precise Poverty Alleviation in Wuling Mountain District -- A Case Study of 18-hole Village, Huayuan County[J] Social Science Journal of Shanxi Higher School, 2016, 2808: 13-15 
[8] Tan Fenglian, Peng Yuwen. The problem and strategy of precision poverty alleviation in rural areas -- Based on the inspiration of precision poverty alleviation in Huayuan County [J]. Hunan Agricultural Science, 2016,08:103-106 